\title{
A new method of using cephalometric measurements in orthodontics (part 2) or how standard deviations can be the practitioner's false friends
}

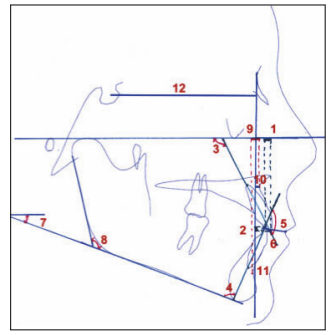

\section{René BONNEFONT, Jean-François ERNOULT, Olivier SOREL C.R.A.N.I.O.M, January 2012}

\section{ABSTRACT}

It is generally agreed that cephalometric analyses of the Americans Ricketts, Steiner, and Tweed are of questionable utility. The C.R.A.N.I.O.M group has formulated a new method of using cephalometric measurements that it believes will be moderately helpful to orthodontists in making their diagnoses.

We analyzed 83 young adults in Class I occlusion who had had no orthodontic treatment.

The most interesting new formulation of our plan was to examine the extremes of the variables that we considered in this population. These figures constituted limits that differed widely from each other: there was more than a $30^{\circ}$ gap between the measurement of the incisor inclined furthest buccally and the one inclined most lingually (or palatally).

Accordingly, for these lower anterior teeth inclinations to Downs's mandibular plane ranging from 78 to $114^{\circ}$ were acceptable. And for the maxillary incisors inclinations to the Frankfort plane varying from 97.5 to $130.1^{\circ}$ are considered to be in a standard range. The need to reposition incisors in order to conform to what we can now see as an abusively rigid normal accordingly occurs much less frequently.

For this reason, orthodontists will find far fewer indications for the extraction of bicuspid teeth than they would in rigidly adhering to the standards imposed by the Ricketts, Steiner, and Tweed cephalometric analyses. We believe that measurements of skeletal, osseous structures merely differentiate between various typologies and do not describe forms that constitute anomalies.

The C.R.A.N.I.O.M group affirms that cephalometrics occupies a position in the array of orthodontic diagnostic tools that comes after the assessment of esthetic, periodontal status, and muscular equilibrium. 


\section{KEYWORDS}

Cephalometrics

Averages

Standard deviation

Extreme values

Incisal inclination

Facial and mandibular forms

Cephalometric repositioning of incisors.

In the last issue we announced that Professor Julien PHILIPPE had written a commentary on our cephalometric analysis.

At the beginning, we had jointly prepared a text that was to serve as an introduction to this article before we knew that it would appear in two parts.

We think that this is not an inappropriate time to print it as originally planned.

René Bonnefont

So here it is, after a little delay...

\section{A PREFACE TO THE CRANIOM ARTICLE ON CEPHALOMETRICS}

As the reader knows, our CRANIOM group sent a copy of its analysis to Pr. Julien PHILIPPE before its publication.

We are pleased to incorporate into this introduction to our article the comments he was kind enough to send us in reply.

Julien PHILIPPE has deftly discerned the three principal points of our new method that he describes in his text, which we cite below. There are, however, other benefits of our plan like, for example, the aid it offers orthodontists in making a differential diagnosis of maxillary and mandibular osseous antero-posterior anomalies.

After having pointed out these interesting improvements, this very distinguished orthodontist then asserted that they hadn't made him change his mind about the inadvisability of using cephalometric measurements as a component of the diagnostic process.

Obviously, he has every right to take this stand and we respect it.

What Dr. Philippe's position does do is to provoke CRANIOM to ask itself this question: has our group gone too far in its use of cephalometrics?

We do not think so, primarily because we have employed cephalometric measurements with thoughtful moderation.

For example, the utilization of limits demarcated by the extreme values of the parameters we studied in our sample opens up a vast range of 
situations that would permit us, among other things, to accept without much change the initial position of our patients' incisor teeth.

Accordingly, in our analysis a mandibular incisor inclination, under certain conditions, anywhere from 78 to $114^{\circ}$ is acceptable.

We leave it to all our readers to form their own opinions about this question.

And to do this, of course, they will have to allow themselves enough time to test it in all of its aspects.

René Bonnefont

\section{Julien PHILIPPE's Commentary}

In sending me the CRANIOM article, René Bonnefont knew that in my view no cephalometric analysis can supply useful therapeutic indications and, therefore, I would not be interested in the first two lines of their essay. We know that the classic American analyses presuppose that the patient's reference lines are well oriented, in harmony with those of their theoretical model. Accordingly, any variations from the model of the patient's measurements would derive from the structure being measured, while in reality they might just as well result from a deviation in the reference line that can vary every bit as much as the structure being evaluated.

Having made this point, I wish to acknowledge that the CRANIOM analysis constitutes progress for many reasons, which include:

1. The recognition that point $N$ is variable. Admittedly, but what about all the other reference land- marks? This recognition has led CRANIOM to replace angle ANB with another cleverly chosen measurement.

2. The restoration of the "line of sight plane" as a physiological way to position the head. This orientation allows the evaluator to take the variability of the SN and Frankfort planes into account; it also makes clear how variable Pellerin's 1984 orientation based on the organs of equilibrium, the semi-circular canals of the inner ear, is.

This position is one that the clinical examination dictates.

3. Their utilization of the extreme values of a normal population is an original idea that improves on by earlier methods by encompassing all the variations of reference lines and structures being observed together, without insisting that variations come only from the observed structures. This is objective and unbiased.

In addition, this type of measurement rescues the practitioner from the ridiculous obsession with the so-called "ideal" average that conflicted with the scientific biological view that any value lying within two standard deviations of either side of the average, that is $95.5 \%$ of all values, is normal. Let us not forget that the world admires the champions and stars, who are anything but average.

To sum up, let me state that this method of analysis seems to me to represent an important improvement over the classical American analyses, without in any way modifying my fundamental opinion that cephalometric measurements do not constitute diagnostic data. 
What this new method does offer the profession is a good descriptive tool, with all the worst errors of the classic analyses stripped away.

But CRANIOM is quite right, in fine, to make subjugate the therapeutic notions to clinical realities.

\section{INTRODUCTION TO PART 2}

We shall now present our method of using, first, the extreme values of our sample and, second, the averages and standard deviations.

These two different utilizations define the new cephalometric that we
And to emphasize the point, let me quote once more, as so many others have done, the timeworn but still eminently sage counsel of my teacher, L. Muller, "Cephalometrics is a good servant, but a bad master."

Julien Philippe

are introducing here:

$$
\begin{gathered}
1 \text { - What are and how do we } \\
\text { employ extreme values? } \\
2 \text { - What are and how do we } \\
\text { employ standard deviations? }
\end{gathered}
$$

\section{HOW AND WHEN TO USE EXTREME VALUES?}

Answer: extreme values are used, essentially, to analyze the inclination of upper and lower incisor teeth.

In obtaining this series of values from our sample we used only measurements taken from individuals who

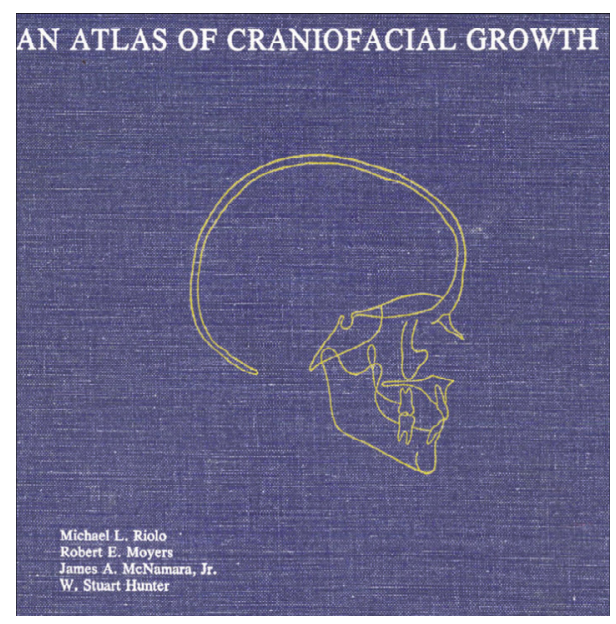

had completed their growth period.

At this stage of the article, it is time for us to report how we accumulated the ensemble of our data.

For one thing our CRANIOM analysis is the first and only one to present the extreme values of every variable. However, our sample contained only individuals whose average age was 20.

And, clearly, for completeness, we ought to be able to present useful measurements from every stage of orthodontic treatment as well as from different stages of the growth period.

To accomplish this, we were forced to extrapolate our data using other well-known and well-recognized studies as guides. We chose:

1 - The Michigan growth atlas,

2- The report of the 1995 SFODF convention in Rennes.

Figure 38 


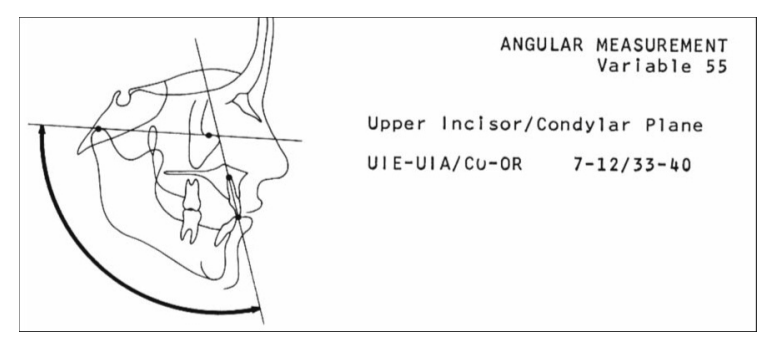

Figure 39 a

1 - An examination of the measurements contained in the Riolo, Moyers, MacNamara, and Hunter Atlas of Craniofacial Growth (Ann Arbor, Michigan, 1974) (fig. 38).

Observations of the inclinations of incisors in $\mathbf{1 6}$ year-olds:

- upper incisors to the Frankfort plane $=111^{\circ}$ (fig. 39 a).

- lower incisors to the mandibular plane $=95^{\circ}$ (fig. 39 b)

The average and standard deviation values of our sample are more or less the same as those of the Michigan Atlas.

\section{2 - Comparison of growth rhythms}

We compared:

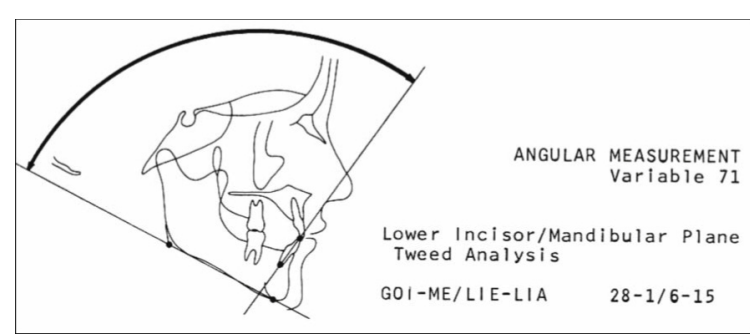

Figure $39 b$

- the facial growth rhythms of French adolescents as recorded by the SFODF Rennes convention of 1995 (fig. 40 a to c), focusing especially on the rhythm of mandibular growth as indicated by the segment, or distance from point $S$ to menton, point Pogonion.

- and the same segments, or distances, defining the rhythms of mandibular growth of subjects in the Michigan study (revue d'ODF, vol. 19, $\mathrm{n}^{\circ} \mathrm{IV}$, October 1985 (fig. 41).

Taking into account the Atlas having followed its subjects from the age of 6

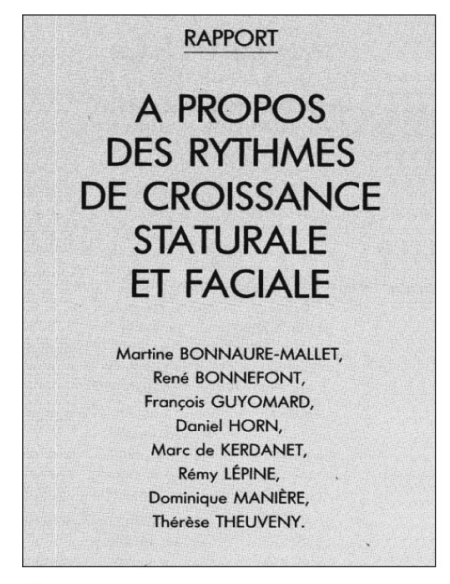

a

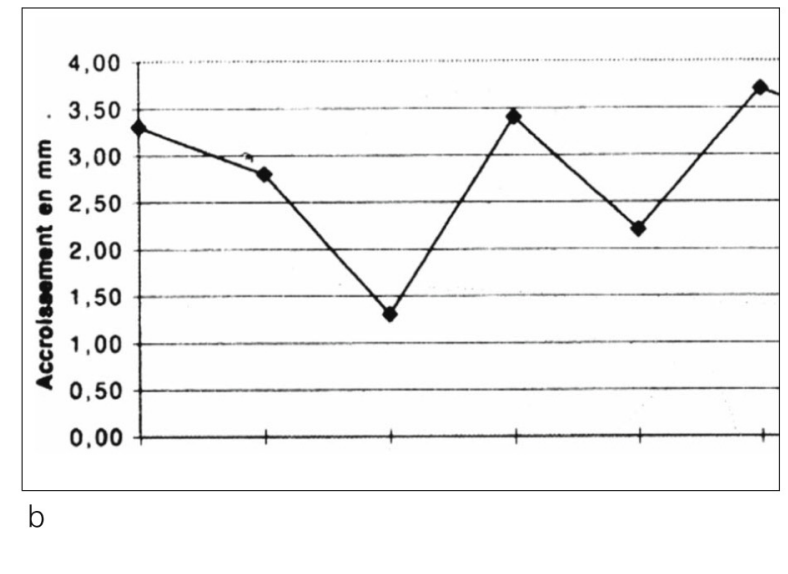

Figures 40 a to $c$

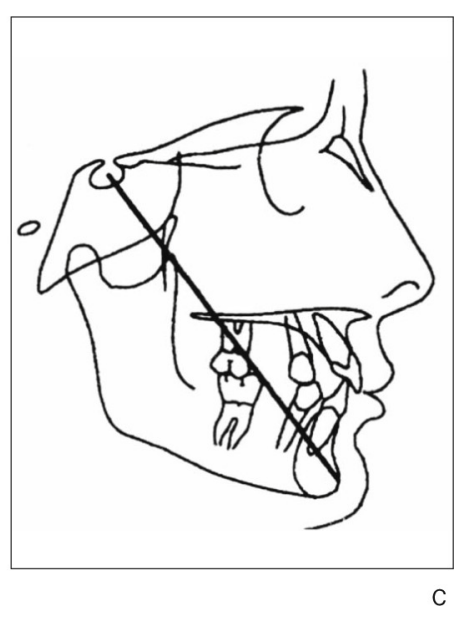

C 


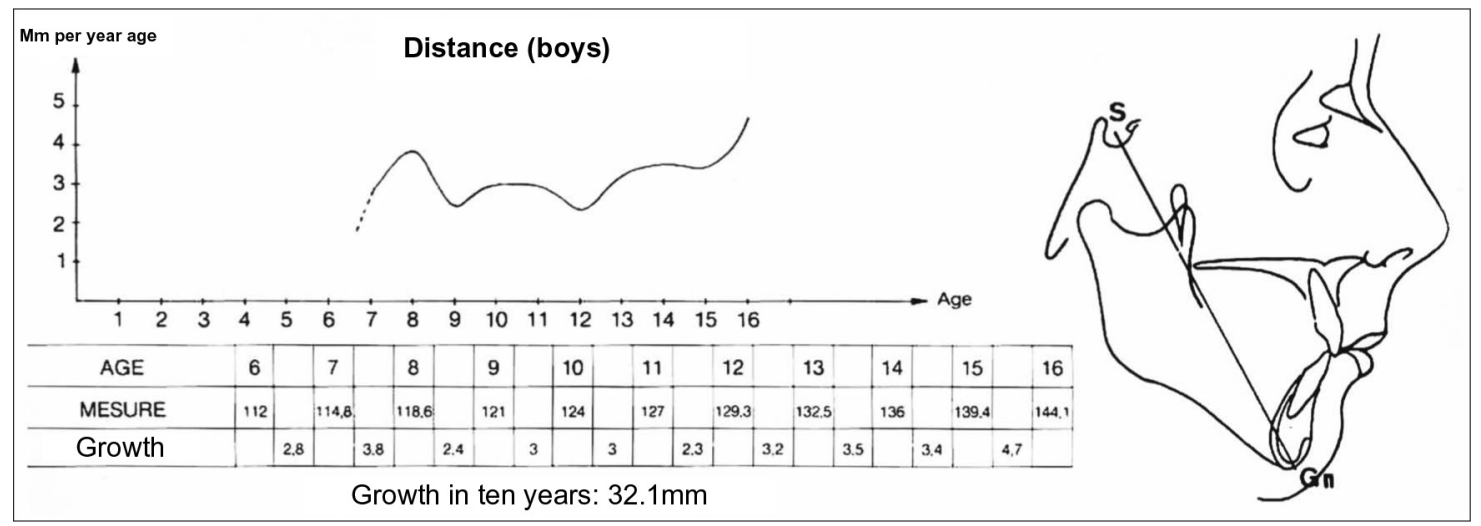

Figure 41

to 16 and the Rennes study only from 9 to 16 , we can conclude that the correlation between the two curves is significantly similar enough to allow us to use the Atlas data for subjects 9 years of age and older.

Whatever differences existed between the two groups were insignificant. Later we shall discuss this in grater detail.

But we can say now, that this procedure in no way differs from what we do in our offices every day when we employ the values presented by North American analyzes like the Ricketts, Steiner, and Tweed to evaluate our French patients.

As we have already said, a general overview of the tracings we made of our sample greatly surprised us by the wide disparity they demonstrated between minimal and maximal values.

And this, let us repeat, is an observation made on a group of subjects who had never been treated orthodontically but were all in Class I occlusion.

\section{Lower incisors}

The inclinations of the mandibular incisors ranged from $\mathbf{7 8}^{\circ}$ (fig. 42 a) to $114^{\circ}$ (fig. 42 b) which is a gap of $36^{\circ}$.

Clearly these figures are very, very far from the $90^{\circ}$ Tweed prescribed and also quite distant from the formulations of others.

Our values can constitute perfectly acceptable limits because we found them in normal subjects who had had no orthodontic treatment.

What is also striking to the naked eye are the two osseous and mandibular forms in the two subjects whose cephalograms are depicted below.

- The head plate on the left, fig. 42 a, shows an individual whose growth was primarily vertical, dolichofacial, or hyperdivergent,

- The head plate on the right, fig. 42 b, shows an individual whose growth was primarily horizontal, brachyfacial, or hypodivergent. 


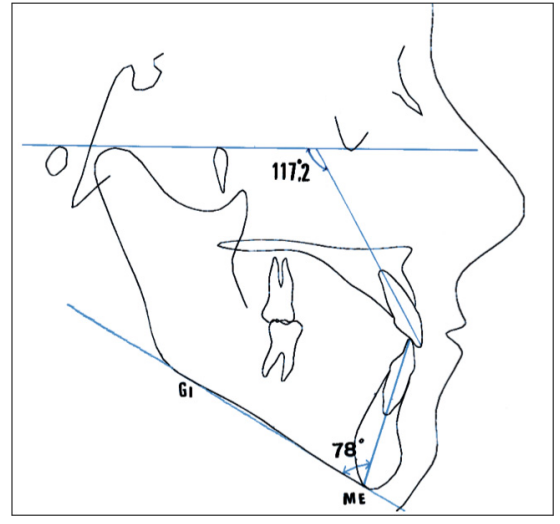

Figure 42 a

The most upright at $78^{\circ}$.
These two figures are copies of the figures 2 and 3 that appeared in Part 1 of this article published in, vol. $14 n^{\circ} 4$ this journal 2010.

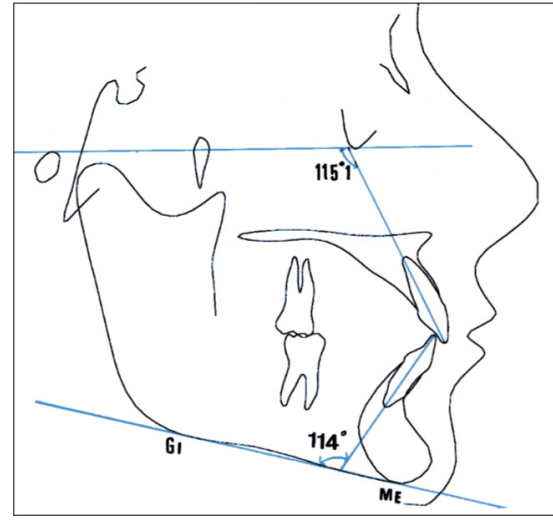

Figure $42 b$

The most buccally inclined at $11^{\circ}$.
We can note here the difference between the situation of individuals whose values are at either end of the limits of our values with the situation depicted by an average value and standard deviations:

If we utilize the classical reference of the average plus or minus two standard deviations we arrive at limits of $82^{\circ}$ and $108^{\circ}$; inclination values rather more narrowly divergent than those of the extreme values, $78^{\circ}$ to $114^{\circ}$.

\section{We can safely say, then, that standard deviations are false friends of orthodontists.}

In order to incorporate these different readings of averages and standard deviations in a single sketch we installed them on an average a tracing of an average cephalogram (fig. 43) that would portray the neighboring skeletal structures in an "average" form and, obviously, without any specific osseous feature, which would be the case with extreme values.
We have already seen that we can immediately notice the differences between skeletal structures by placing two tracings (1 and 2), as we have done below, side by side (fig. 44 and 45).

Moreover, in our sample the calculation of the correlation coefficient showed a significant relationship between facial type and lower incisor inclination:

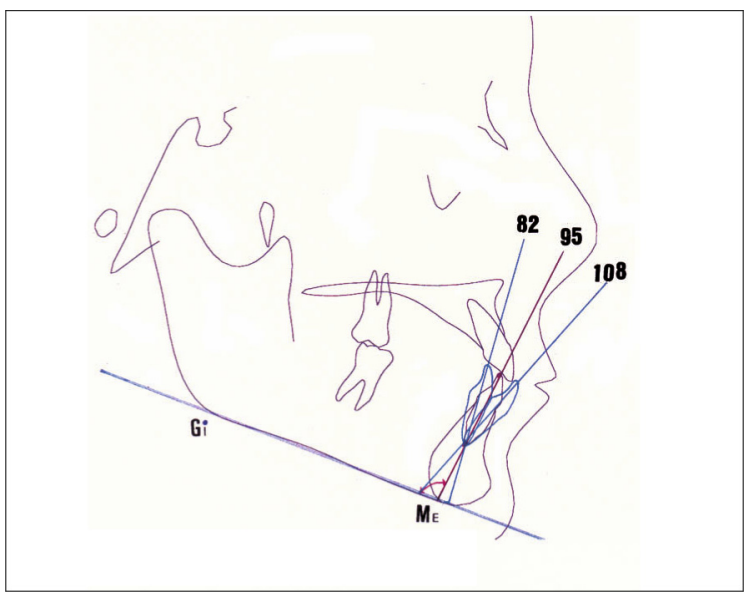

Figure 43 


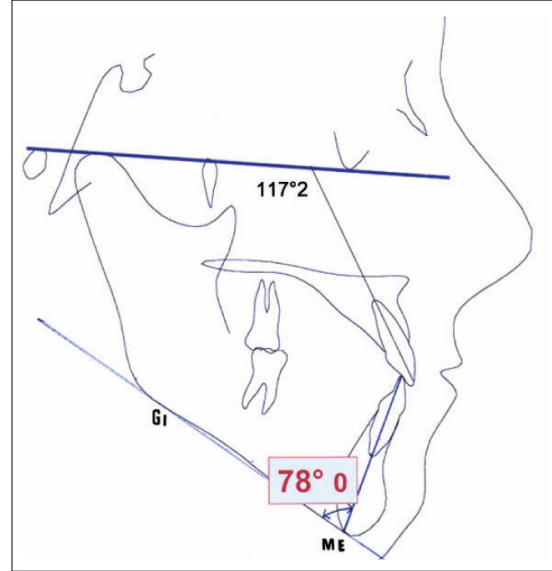

Figure 44

The most lingual lower incisor angulation.

- the more the lower incisor is inclined lingually the more the facial type will tend toward the vertical;

- the more the lower incisor is inclined lingually the more the facial type will tend toward the horizontal.

\section{Extreme inclinations of upper in- cisors}

The inclinations of upper incisors to the Frankfort plane varied from $97.5^{\circ}$ (fig. 46) to $130.1^{\circ}$ (fig. 47), which is, accordingly, a gap of $32.6^{\circ}$.

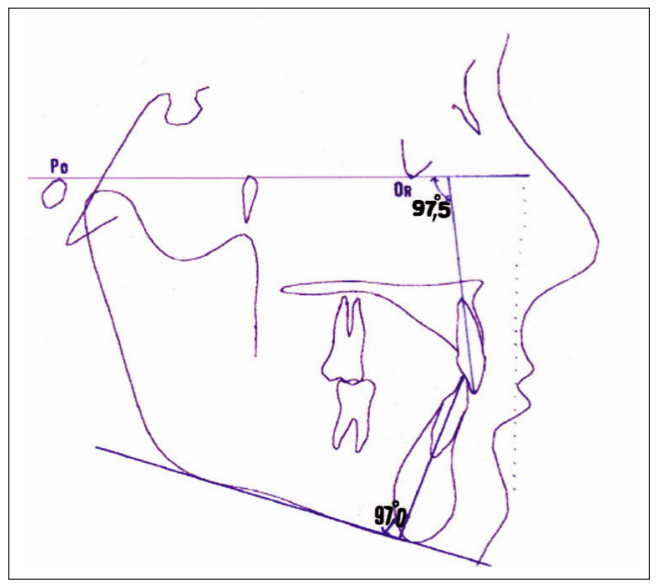

Figure 46

The most palatally inclined maxillary incisor at $97.5^{\circ}$.

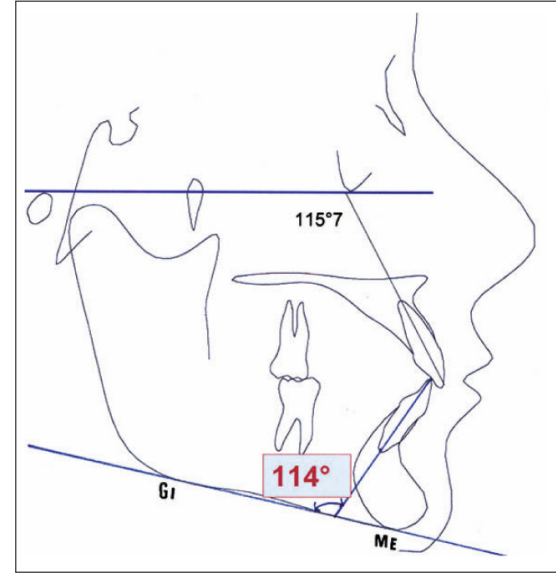

Figure 45

The most buccal lower incisor angulation.

What is most striking at first glance is the difference in the skeletal type, the relative antero-posterior protrusion of these two subjects:

- the one on the left (fig. 46) represents skeletal Class II type, where the upper incisor has had to lead extensively toward the palate in order to maintain contact with the lower incisor, in other words there has been a considerable compensation characterized by a strong palatal inclination of the maxillary incisal teeth;

- the one on the right (fig. 47) represents a highly pronounced skeletal Class III type, where the upper incisor has had to tilt buccally in a pronounced fashion in order to keep in contact with the lower incisor, in other words, this is also an instance of extensive dental compensation, this time buccally.

We have already pointed out that these two subjects in our sample whose incisor teeth demonstrated the most extreme inclinations had found these positions altogether acceptable and never thought of having 


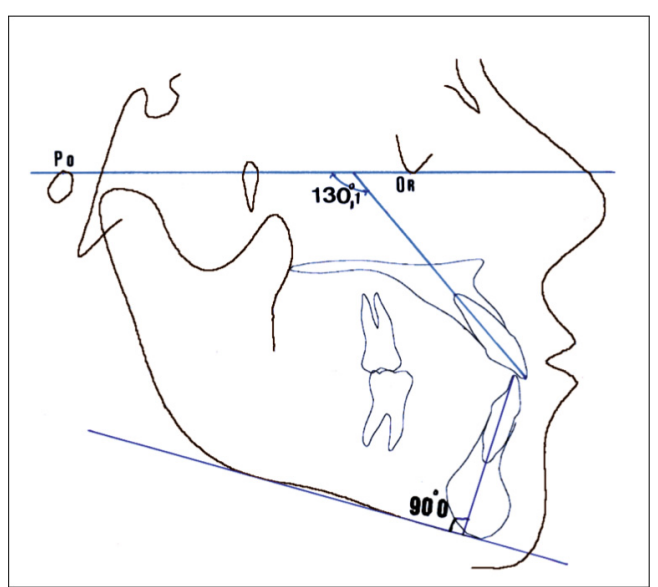

Figure 47

The most buccally inclined maxillary incisor at $130^{\circ}$.

them "corrected," which would lead an observer to think that there was nothing unpleasing in the appearance of these two incisor inclinations despite the gap of $32.6^{\circ}$ that separated them.

An inspection of the net difference between the skeletal structures of the four subjects presenting extreme values is of especial interest.

It indicates that we cannot associate the extreme inclinations of upper and lower incisors on the same tracing because they exist in patients whose facial forms and skeletal protrusions are not comparable.

For example, if we wanted to compensate for a Class III type skeletal protrusion by changing the inclination of incisor teeth, it is not possible to associate the lowest mandibular incisor inclination, $78^{\circ}$, with highest upper incisor angulation, $130^{\circ}$.

It is, therefore, not possible to join them artificially, on the tracing of the same subject. That would constitute a representation of a cephalogram that could not exist.
In this situation, which is quite infrequent, the question must, then, be asked, what value must be given to the inclination of the incisor antagonist to an extreme value incisor in the other jaw.

We believe that is useful to analyze the inclinations of the incisor teeth that, on a tracing, are antagonist to incisors representing extreme values.

Analysis of the degrees of inclination of incisors antagonist to extreme value incisors on tracings of subjects with the most extreme values of our sample

- Maximal values

- If the lower incisor $=114^{\circ}$ the inclination of the upper incisor $=$ $115.1^{\circ}$ (fig 48).

- If the upper incisor $=130.1^{\circ}$ the inclination of the lower incisor $=90^{\circ}$ (fig. 49).

\section{- Minimal values}

- If the lower incisor $=78^{\circ}$ the inclination of the upper incisor $=$ $117.2^{\circ}$ (fig 50).

- If the upper incisor $=97.5^{\circ}$ the inclination of the lower incisor $=$ $97.0^{\circ}$ (fig. 51).

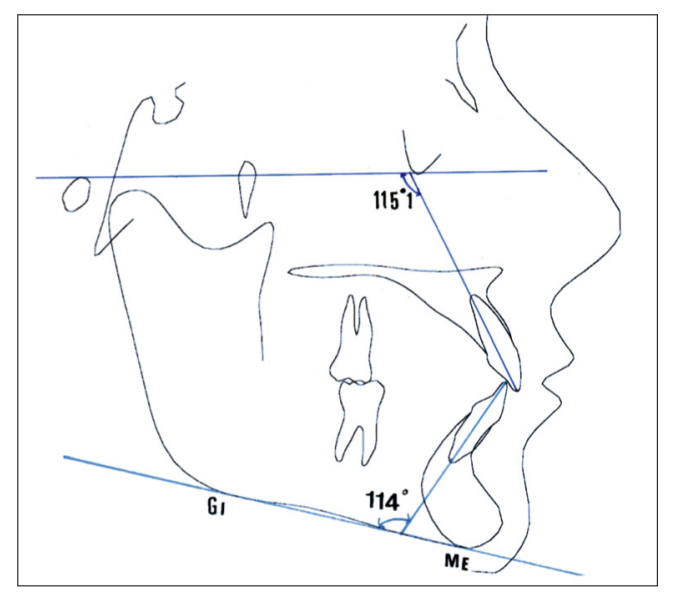

Figure 48 


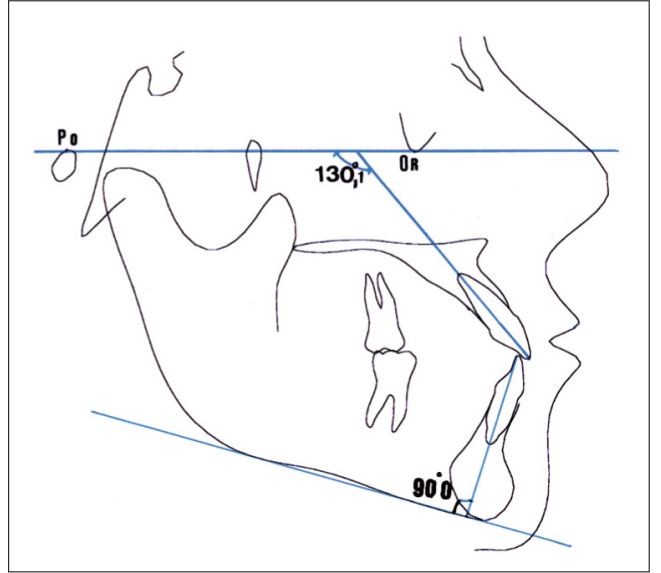

Figure 49

We believe it is necessary to take this inclination of the incisor antagonist to incisor of the high reference value in the case of a real subject from our sample that we have just presented.

Thus, for example:

- the subject whose mandibular incisor had the low inclination value of $78^{\circ}$ had a maxillary incisor inclined at $117.2^{\circ}$.

- the subject whose mandibular incisor was angulated at the high value of $114^{\circ}$ had an upper incisor inclined at $115.1^{\circ}$.

Without going into detail about the methodology of the Ricketts, Steiner, and Tweed analyses, we should remember that, for example, the outer limits of these appraisals were based on variable averages that differed from analysis to analysis.

But we cannot utilize the extreme values from any of them because they were not published.

We feel that we must emphasize that the standard deviations of the Class I cases in our sample of subjects

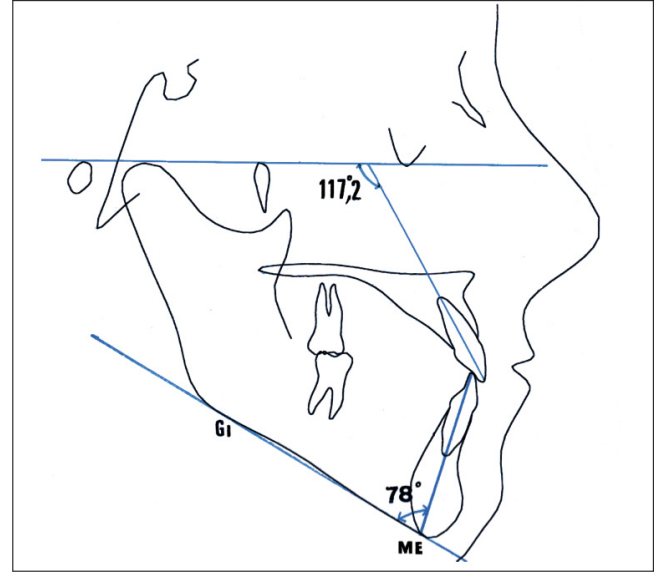

Figure 50

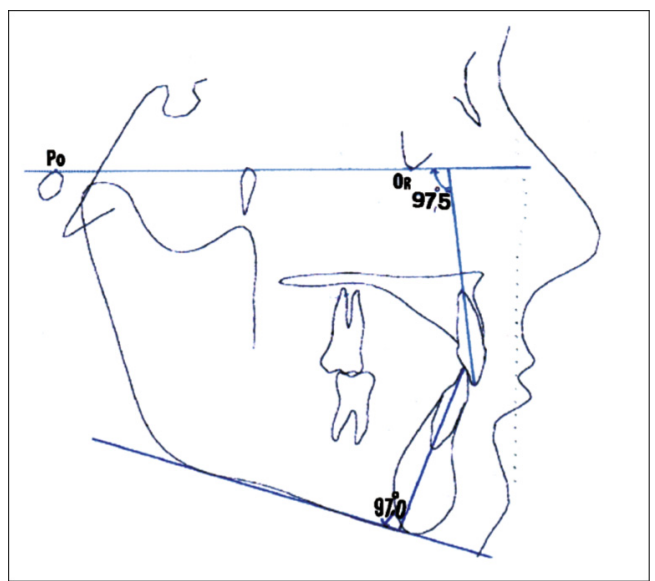

Figure 51

who had never had orthodontic treatment did not, as the extreme value cases did, portray situations not acceptable cephalometrically.

It would be logical to conclude that subjects with inclinations values located well between within the limits on either extreme would be considered normal.

But we cannot add that these initial incisor readings are equally normal clinically because they are the result 
of the influence of the growth of this subject in a general sense and of the muscular equilibrium in a specific sense.

And we all know the essential role that the muscular system plays in the inclination of teeth.

Thus cephalometrics can play a role in the decision of whether or not to accept the initial position of the lower incisor.

We also clearly understand that this is also the case of other analyses with the major difference concerning incisor inclination: we take into account extreme inclinations as reference limits.

In our new cephalometric method we propose the following rule for the management of incisor teeth:

\section{We must:}

- accept as cephalometrically normal the inclination of the incisors of the patient being examined when the value falls between the extreme limits, which are:

- between 78 and $114^{\circ}$ for lower incisors, and

- between 97.5 and $130^{\circ}$ for upper incisors;

- and decide to adjust the incisor inclinations when, initially, they fall outside these extreme limits and, therefore, can be considered cephalometrically to be in a pathological condition.

There should be a discussion to elucidate this point: it is clear that this appreciation is uniquely cephalometric. It does not touch on other essential notions like the position of roots within bone, the periodontal status, muscular equilibrium, or overall esthetics.

Let us add that the practitioner using this framework is not obliged to accept original incisor inclination even if it falls within our described limits.

Practitioners may want to modify incisor position to achieve stability by placing it more comfortably within the dental corridor that respects well known rules of muscular balance even if that initial position falls within our described extreme limits.

And, happily, we have observed that we can achieve stability for incisors by moving them therapeutically. If this were not axiomatic, orthodontic treatment without relapse would not be possible.

But we should remember that the initial position of the incisor was a point of the best balance, so keeping it at the same angulation is the surest way to maintain stability.

\section{HOW AND WHEN TO USE AVERAGS AND STANDARD DEVIATIONS?}

Answer: averages and standard deviations are used only to define and classify different shapes of skeletal structures. They are never employed to assess the positions of teeth

What seems to us a reasonable procedure is essentially to classify subjects' conformance to categories defined in advance.

We do not, at this point, introduce the concept of normality as is so often done in descriptions. The subjects of our study are neither normal nor abnormal. 
For example, to classify individuals according to size they are said to be big, average, or small, which is nothing more than an observation.

In statistics, we know that a biological norm utilizes on the average, more or less, two standard deviations to define observed limits.

We have preferred in our work to use only one standard deviation as a base for our classification.

In effect, if we had selected two standard deviations, only $5 \%$ of the subjects would have been classified outside the average category, which would have deprived this typology of any interest.

We shall now enumerate the different categories we retained without giving any figures.

All the figures, averages and standard deviations, are reproduced in the synthetic record we assembled.

\section{Classification of the vertical ske- letal structures}

\section{- Facial form}

This will be described in three forms, vertical (fig. 52), average (fig. 53), or horizontal (fig. 54).

\section{- Shape of the mandible}

Similarly, this will be described as vertical (fig. 55), average (fig. 56), or horizontal (fig. 57).

\section{Classification of horizontal skele- tal structures or basal bone discre- pancies}

The variable measured here is the one CRANIOM selected, that is the segment $A^{\prime} B^{\prime}$ (or $A^{\prime \prime} B^{\prime \prime}$ ), defined by the orthogonal projections of points $A$ and $B$ on the Frankfort plane (fig. 58).

In this framework, three skeletal categories can b postulated:

- type III (fig. 59),

- type I (fig. 61),

- type II (fig. 60).

\section{- Observations}

An analysis of the ensemble of these cephalograms clearly shows how the teeth and the skeletal structures are independent of each other.

But we knew already that this study would clearly show that.

In this spirit, Ballard in 1951 had introduced the concept of skeletal protrusions in order to distinguish between dental classes and skeletal classes.

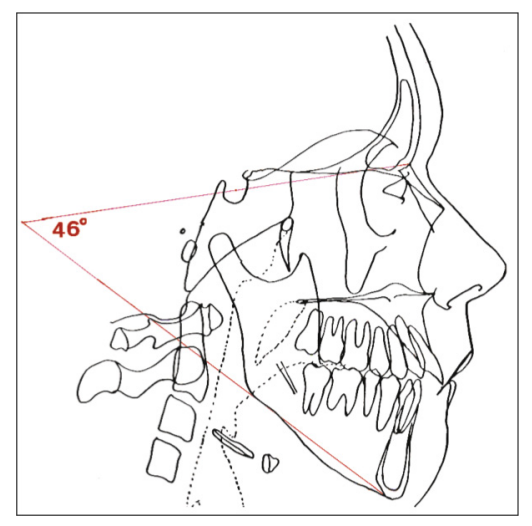

Figure 52

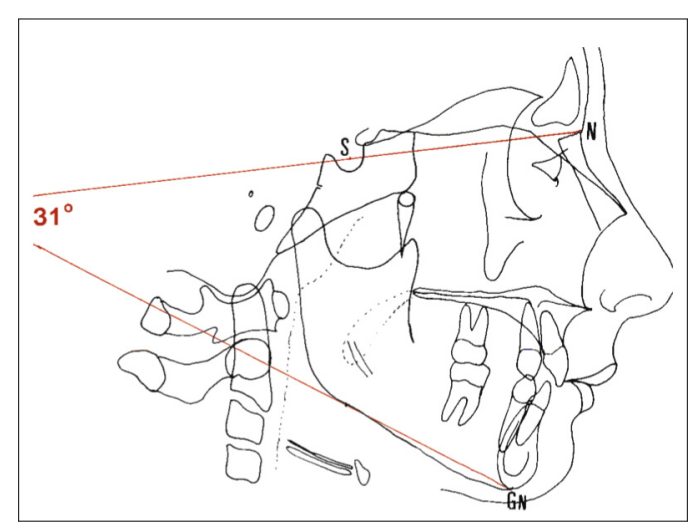

Figure 53 


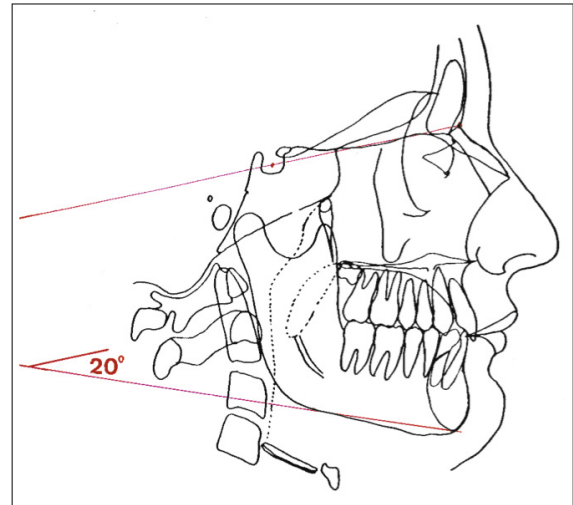

Figure 54

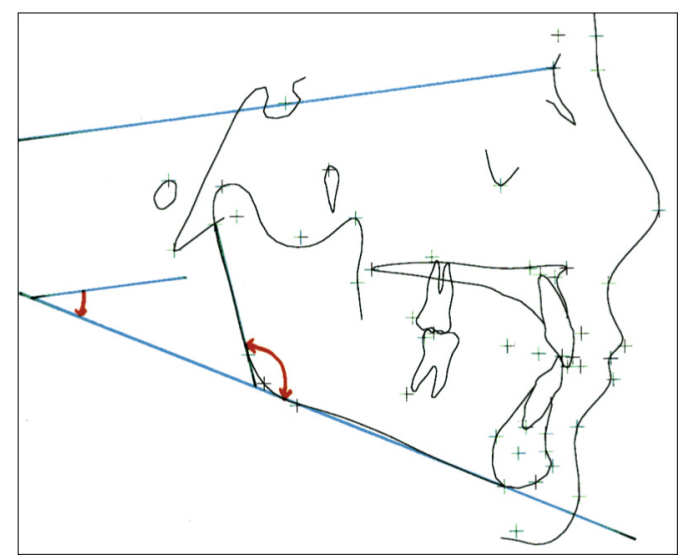

Figure 56

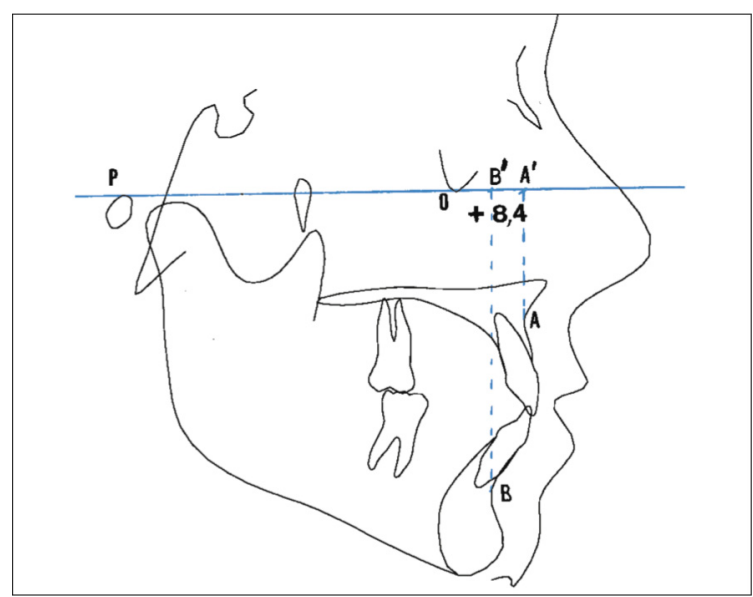

Figure 58

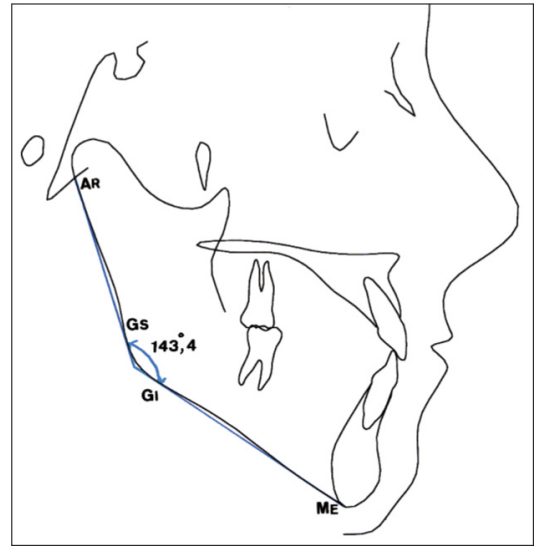

Figure 55

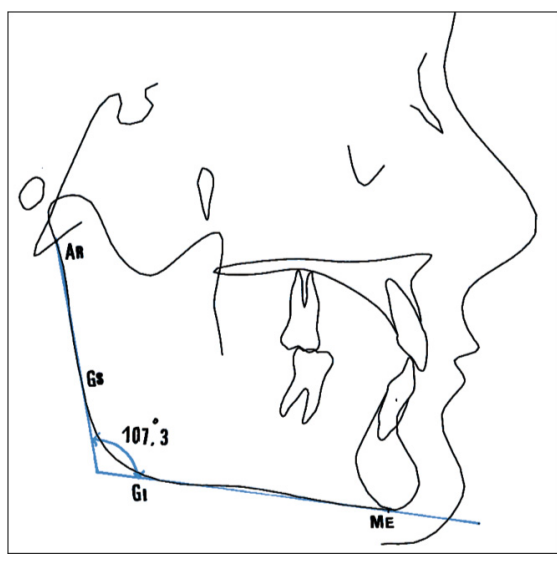

Figure 57

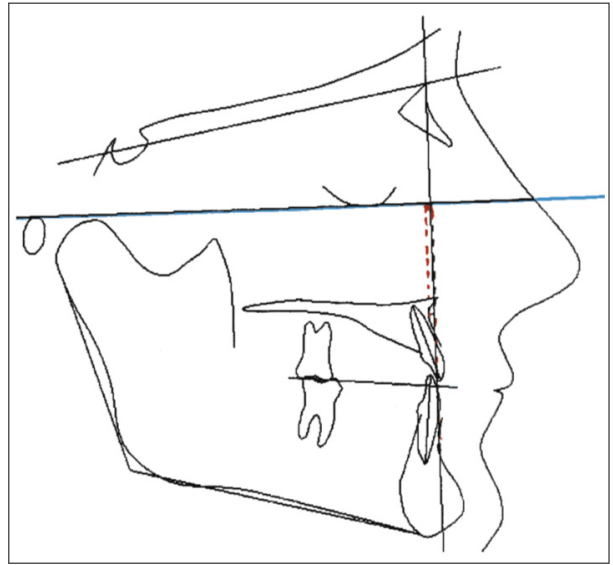

Figure 59 


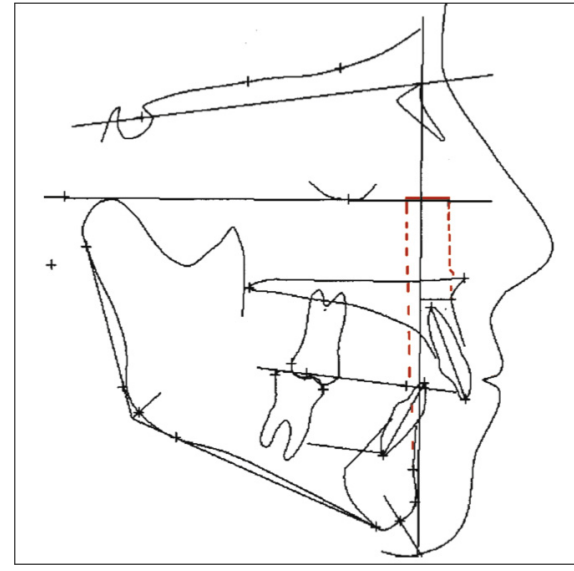

Figure 60

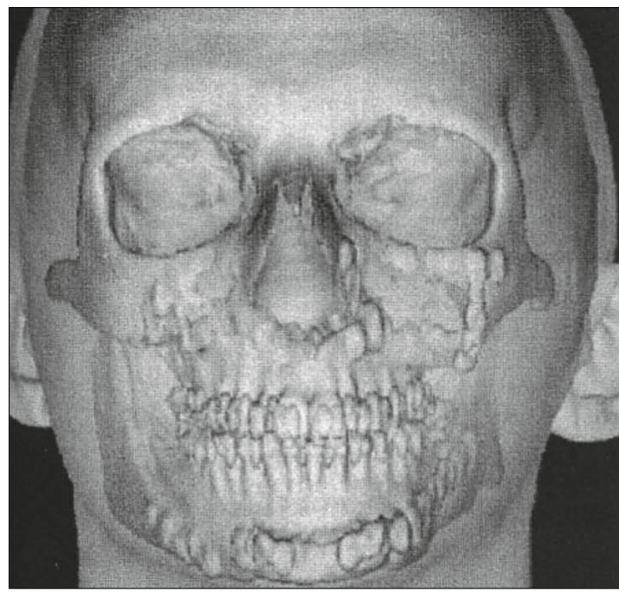

a

Figures $62 a$ and $b$

Today, it seems to us that we can clarify the concept more explicitly by using the following terms: class, to

\section{CONCLUSION}

We have divided this last chapter into two parts.

- In the first section we shall review the important differences between our cephalometric analysis and all the others.

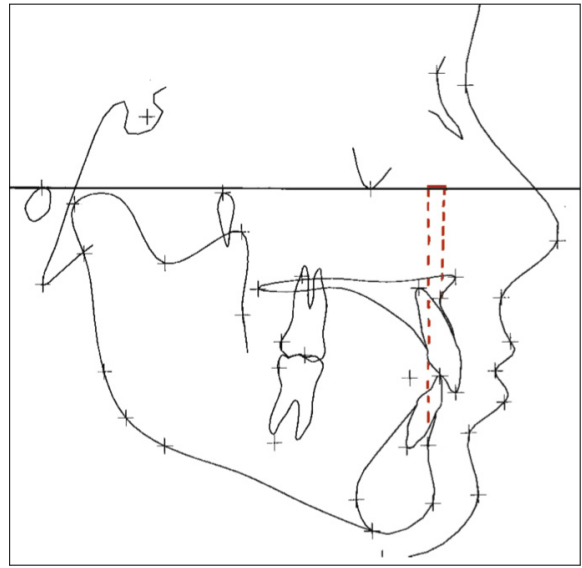

Figure 61

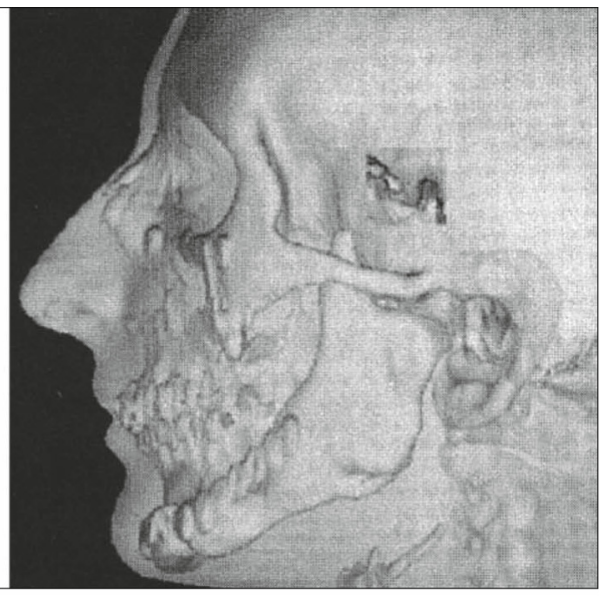

b designate dental discrepancies and type to designate skeletal discrepancies.
- Our reference sample was composed of 83 young French adults, all of whom had Class I dental occlusions but had never had orthodontic treatment; so by definition all the measurements we made on 
their cephalograms were acceptable. We collected our records at the faculties of dentistry of Rennes and Nancy. We began our analysis by dividing them into two different groups controlled by statistically compatible means and then joined them to form a homogenous group.

- We used the measurements of skeletal structures only to classify them into different types that did not constitute anomalies.

In order to focus on discrepancies between basal bone structures we eliminated variables using point Nasion because this landmark biases every measurement containing it.

- On the other hand, for the teeth, we selected from the records the extreme values of the inclinations of the upper and lower incisor teeth. We were quite astonished at the large gap that separated the extreme values at either end of the spectrum:

- 32.6 $6^{\circ}$ for the upper incisors, the most buccal inclination having been $130.6^{\circ}$ and the most palatal $97.5^{\circ}$;

- and $34^{\circ}$ for the lower incisors, the most buccal inclination having been $114^{\circ}$ and the most lingual $78^{\circ}$.

The measurements describing the extreme inclinations of the incisor teeth are sufficiently large to accommodate any type of movement orthodontists might determine to apply to them.

Each extreme tooth value corresponds to a well-defined skeletal form; they are not interchangeable.

The reader can easily see that the diverse inclinations deemed acceptable in our analysis diverge greatly from the average figures proposed in all the North American cephalometric analyses, concepts that we now consider to be outdated.

But, nevertheless, we have not forgotten the benefits that these American pioneers bestowed on the profession.

We defended the Steiner analysis ardently from the dais of the S.FO.D.F. convention of 1966 and did the same for Ricketts in the 1970 session of Actualités OdontoStomatologiques.

We have based our position on the critical analyses of these predecessors.

The four extreme inclinations of incisor teeth in our sample constitute LIMITS that are broad enough to quite often permit orthodontists to accept the initial incisor inclinations of their own patients.

And, as a result, orthodontists may now less frequently have to resort to the extraction of bicuspid teeth in order to place incisors in some arbitrary preconceived position.

\section{- In the second part, we present a general reflection containing related perspectives.}

We conducted this study using socalled conventional two-dimensional cephalogram. But we are convinced that it would have been even more instructive if we had been able to evaluate a sample of 83, or more, subjects with three-dimensional cephalometrics (fig. 62).

We are indebted to Professor Jean CASTEIGT for suggesting the innovative idea of attempting to assess in its full volume, not as a flat plane. 
The principal benefit derived from a Three Dimensional analysis is that it gives endows the picture with the reality of the true size of skeletal structures, a picture that is important in evaluating the cortical bone investing lower incisor teeth labially.

Independent of the values of the extreme limits, it is this thickness of lower anterior labial bone that determines whether mandibular incisor teeth can be moved labially.

But the periodontal examination of this region is more critical than the cephalometric.

We hope to be able to replicate this study with Three Dimensional data in the near future.

Before we conclude this article we are eager to make the stance that our CRANIOM group takes on the position that orthodontists should consider cephalometric occupies in the management of their specialty.

Like most of our colleagues, we believe that clinical assessments in general deserve first place in our attentions, including in this panoply periodontal exams, a variety of functional studies, and esthetic evaluations.

However, we believe that it would be a great mistake to reject totally the contributions that cephalometrics can make. And the distinctive way we employ head X-rays is ours alone.

As we said earlier, we have rejected the North American analyses that gave us our introduction to cephalometrics.

But we are determined not to be bound by earlier approaches that may not have been sufficiently well thought out...

That is why we have devised the new concept that we have just presented for your inspection.

And we shall be delighted to give serious attention to any suggestions you would be kind enough to make about it.

We are quite ready to employ other methods on the condition that they provide useful information for devising treatment strategies, which, alas, is not really true of the North American analyses that are still far too often utilized in orthodontic offices.

We count ourselves members of the group that believes all those responsible for teaching orthodontics and for disseminating information about cephalometrics should unite to reflect on whether or not we should maintain the status quo.

And if this group of thinkers decides to select a new analysis it does not matter whose brainchild it is so long as it fulfills the requirements we have discussed in our presentation.

N.B.

While we do not, of course, endorse any specific soft ware company, we are persuaded that in the year 2011 cephalometrics has to be fully digitized.

Among the many programs now available, we do note that one version, distributed by a French computer company specializing in dental information technology, has a number of advantages.

This soft ware program, distributed by a company based in Valence 
(Drôme) offers precise measurements with zero risk of calculation error and presents a reasoned and reasonable interpretation. It also offers a helpful management incisor positioning and repositioning together with automatic digitized superimpositions of all types for photographs, cephalograms, and digitized tracing of the kind we used in this article.

\section{ACKNOWLEDGEMENTS}

We want to extend our warm thanks to Professor Claude Charron who calculated all the aspects of the statistics employed in our study with his attention and competence that are the hallmarks of all his activities.

We also offer our appreciative thanks to Yves Barat, a former editor-in-chief of this journal for his intelligent and experience based advice and to Baltazard da Sylva, the information technologist who managed, with a great deal of competence and always congenial availability, the integration of our CRANIOM documentation into Odrade cephalometric soft ware program.

\section{WORKS TO CONSULT}

A.A propos du décalage sagittal des mâchoires et de sa mesure céphalométrique. Rev Orthop Dento Faciale 1979;13:267-276.

Bolender Y, Deblock L, Theuveny T, Turlot JC, Bolender C. Comparaison des analyses céphalométriques de Björk, Ricketts et Sassouni ainsi que des mesures de Mac Namara et du Wits. Rev Orthop Dento Faciale 1986;20:251-272.

Bonnefont R. Contribution à l'utilisation pratique de la méthode d'analyse céphalométrique de Steiner. Orthod Fr 1966;37:623.

Bonnefont R, Chauvois A, Delamaire M, Geslin JC. La céphalométrie. Pourquoi ? Orthod Fr 1977;48:639.

Bonnefont R, Ezvan A, Lepine R, Sorel O, Benamed M. La céphalometrie actuelle, aide au diagnostic. Orthod Fr 1995;66:173.

Bonnefont R. Sorel O. Ernoult JF. La céphalométrie du Groupe C.R.A.N.I.O.M. : ses divers aspects «dont la lecture horizontale». Orthod Fr 1995;66:889.

Bonefont R. La prédiction de croissance selon l'analyse de Ricketts. Act Odontol 1971;96:509.

Casteigt J. Une nouvelle construction céphalométrique tridimensionnelle. Orthod Fr 1997; 68(1):171.

Chabert G., Bounoure G. M., Theuveny T. La ligne de Mc Namara : intérêt et fiabilité. Rev Orthop Dento Faciale 1985;19:549-562.

Darqué J. Décalage de base étude de 2 estimations céphalométriques. Orthod $\mathrm{Fr} 1978$; 49:763.

Dutertre E, Bonnefont R. Étude critique des chevrons de Steiner. Orthod Fr 1994;65:243.

EzvanManièreA. Céphalométrie et décalage des bases. Rev Orthop Dento Faciale 1987; 21:305-309.

Horn J, Englebert M. L'analyse de Tweed Une approche originale de l'analyse de l'espace total de la denture. Rev Orthop Dento Faciale 1978;12:165-171.

Izard G. Choix d'un plan horizontal d'orientation en orthodontie. Orthod Fr 1922;1:85. 
Kimmel F, Deblock L, Turlot JC, Theuveny T, Bolender CJ. Vers une synthèse des analyses de Björk, Ricketts et Sassouni, ainsi que des mesures de Mac Namara et du Wits. Rev Orthop Dento Faciale 1986;20:273-287.

Muller L. Utilisation des méthodes d'analyse céphalométrique. Orthod Fr 1955;26:411.

Philippe J. Jetons I'analyse céphalométrique en tant qu'aide au diagnostic. Orthod Fr 1995; 66:753.

Ricketts RM. Nécessité de la céphalométrie en clinique orthodontique actuelle. Traduction de A. Benauwt et J. Praud. Rev Orthop Dento Faciale 1975;9:293-304.

Ricketts RM, Langlade M. Plaidoyer pour une orientation céphalométrique. Rev Orthop Dento Faciale 1977;11:161-172.

Treil J, Faure J. Une nouvelle analyse céphalométrique tridimensionnelle. Orthod Fr 1995; 66741. 